\title{
Lower Motor Neuron Facial Nerve Palsy in a 4-month-old Infant Associated with Chicken Pox: A Case Report
}

\author{
Manakkattu Thekke Peedikayil Mohammed ${ }^{1}$, Ravikumar Payora², Kizhakke Veettil Radhamani ${ }^{3}$
}

\begin{abstract}
Background: A rare case of lower motor neuron (LMN) facial palsy in a 4-month-old infant, following chicken pox.

Case description: A 4-month-old boy was brought with deviation of angle of mouth to the left side and inability to close the right eye, about 10 days after the onset of varicella rashes. The baby did not have any other problem. LMN facial palsy was diagnosed and treated with acyclovir along with a short course of prednisolone. Follow-up, 8 weeks after starting treatment, showed complete recovery of facial palsy.

Message: LMN facial palsy is a rare complication of varicella infection. This is the youngest patient known to us so far.

Keywords: Acyclovir, Lower motor neuron facial palsy, Varicella infection.

Pediatric Infectious Disease (2020): 10.5005/jp-journals-10081-1253
\end{abstract}

\section{INTRODUCTION}

Varicella (chicken pox) is a vesiculobullous eruption, commonly seen in children, caused by varicella zoster virus (VZV). Complications of VZV occur more commonly in immunocompromised patients. Neurological complications are generally rare and estimated to be around $0.01-0.03 \% .^{1}$ Meningoencephalitis, acute cerebellar ataxia, acute transverse myelitis, ${ }^{2}$ and Guillain-Barre syndrome are the usual neurological complications. Lower motor neuron (LMN) facial palsy is rare as a complication of VZV infection, which may develop 5 days before and 16 days following the appearance of the rash. We report a case of LMN facial palsy following chicken pox in a very young infant of 4 months' age.

\section{Case Description}

A 4-month-old baby boy, the second child of a nonconsanguineous couple, was brought with complaints of "narrow left palpebral fissure" compared to the right eye. The baby had low-grade fever and varicelliform rashes 10 days ago. There was history of contact with chicken pox. The baby was feeding well and there were no other significant complaints. Perinatal and neonatal periods were unremarkable, birth weight was $3.2 \mathrm{~kg}$, and the baby has been immunized with all the three doses of primary vaccines as per National Immunization Schedule (NIS). Physical examination revealed wide palpebral fissure and incomplete closure of the right eye, and there was deviation of angle of mouth to left while crying (Fig. 1). There were healing rashes of varicella and scab formation. There were no active vesicles or lesions. There were no other neurological deficits. All other system examinations were essentially normal. Since the diagnosis of facial palsy and chicken pox was clinically evident, no imaging procedures or serological tests were performed. The baby was given oral acyclovir for 7 days along with prednisolone $1 \mathrm{mg} /$ $\mathrm{kg}$ for 1 week and 1 week taper. Artificial tears were given to prevent exposure keratitis. Manual facial nerve area massage also was advised.

Follow-up of the child after 2 months revealed complete recovery of the facial palsy.

\section{Discussion}

Neurological complications associated with VZV infection are rare and is about 1 in 10,000 cases. ${ }^{3}$ Meningoencephalitis, acute
${ }^{1-3}$ Department of Pediatrics, Government Medical College, Kannur, Pariyaram, Kerala, India

Corresponding Author: Manakkattu Thekke Peedikayil Mohammed, Department of Pediatrics, Government Medical College, Kannur, Pariyaram, Kerala, India, Phone: +91 9446844884, e-mail:drmtpmohd@ gmail.com

How to cite this article: Mohammed MTP, Payora R, Radhamani KV. Lower Motor Neuron Facial Nerve Palsy in a 4-month-old Infant Associated with Chicken Pox: A Case Report. Pediatr Inf Dis 2020;2(3):107-108.

Source of support: Nil

Conflict of interest: None

cerebellar ataxia, acute transverse myelitis, ${ }^{2}$ and Guillain-Barre syndrome are the usual neurological complications. LMN facial palsy is an extremely rare complication of varicella. It can be unilateral or bilateral. In a study conducted with 60 patients, including adults and children, with neurological complications associated with VZV infection, encephalitis was the most common (23.3\%) and facial

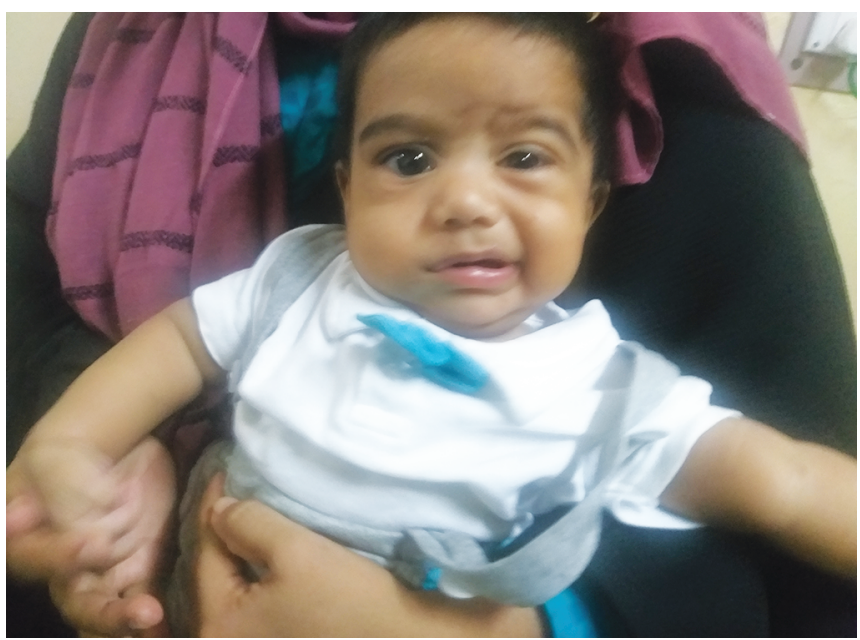

Fig. 1: Baby with right-side LMN facial palsy

(c) The Author(s). 2020 Open Access This article is distributed under the terms of the Creative Commons Attribution 4.0 International License (https://creativecommons. org/licenses/by-nc/4.0/), which permits unrestricted use, distribution, and non-commercial reproduction in any medium, provided you give appropriate credit to the original author(s) and the source, provide a link to the Creative Commons license, and indicate if changes were made. The Creative Commons Public Domain Dedication waiver (http://creativecommons.org/publicdomain/zero/1.0/) applies to the data made available in this article, unless otherwise stated. 
palsy was seen in $8.3 \%$ of patients. ${ }^{4}$ Facial nerve paralysis can occur before, during, or after rashes. ${ }^{5}$ That is from 5 days before and 16 days after the onset of the rash. In our case, the facial palsy appeared 10 days after the onset of rash.

The youngest patient previously reported to have facial palsy and varicella was by Takeshi et al. ${ }^{6}$ They have reported a 4-monthold baby who developed facial palsy before the eruption of varicella. In our case, the baby is 4 months old and the facial palsy developed 10 days after the onset of the rash.

The relationship with varicella and facial palsy is not completely understood; two possible mechanisms to explain the nerve involvement in varicella are direct viral invasion of the nerve ${ }^{7}$ and nerve damage associated with the immunologically mediated mechanism. ${ }^{8}$

There is no definite treatment guideline for the treatment of varicella-associated facial palsy. Various case reports show that a common mode of treatment is with acyclovir, prednisolone, or combination of both. In our case, since the baby presented to us on the 10th day, and with lesions just scabbing, we had treated with oral acyclovir along with prednisolone at $1 \mathrm{mg} / \mathrm{kg} /$ day. Both were given for 1 week and prednisolone tapered over next 1 week. Prognosis is generally good and $80 \%$ of the affected children will recover completely, ${ }^{9}$ whether treated with acyclovir and/or steroid.

\section{Conclusion}

LMN facial palsy, though rare, can occur as a complication of VZV infection. It can occur to infant as young as 4 months. Acyclovir and prednisolone combination treatment may hasten recovery and should be considered.

\section{References}

1. Yilmaz C, Çaksen H. Severe neurological complications of chickenpox: report of four cases. Eur J Gen Med 2005;2(4):177-179. DOI: 10.29333/ ejgm $/ 82340$.

2. Philip SL, Mona M, Anne AG. Nelson text book of Paediatrics. 21st ed., vol. 1. Elsevier; p. 1711

3. Gnann Jr JW. Varicella-zoster virus: a typical presentations and unusual complications. J Infect Dis 2002;186(1):S91-S98. DOI: $10.1086 / 342963$.

4. Shiihara H. Neurological complications of varicella-zoster virus (VZV) infection. No To Hattatsu 1993;25(2):128-134.

5. Odemis E, Turkay S, Tunca A, et al. Acute peripheral facial palsy during chickenpox in a child. J Pediatr Neurol 2004;2(4):245-246. DOI: 10.1055/s-0035-1557228.

6. Tanaka T, Iwai K, Sudo M. A case report of facial nerve palsy in an infant associated with chickenpox. Pract Otorhinolaryngol 2001;94:421-425. DOI: 10.5631/jibirin.94.421.

7. Peters AC, Versteeg J, Lindeman J, et al. Varicella and acute cerebellar ataxia. Arch Neurol 1978;35(11):769-771. DOI: 10.1001/ archneur.1978.00500350073016.

8. Miller HG, Stanton JB, Gibbons JL. Parainfectious encephalomyelitis and related syndromes: critical review of neurological complications of certain fevers. Q J Med 1956;25(100):427-505.

9. Rama Rao GR, Amareswar A, Kishan Kumar YH, et al. Isolated facial palsy in varicella. Indian J Dermatol Venereol Leprol 2008;74(3): 261-262. DOI: 10.4103/0378-6323.41377. 